\title{
Buenas prácticas de e-learning: estudio de caso del e-portafolio
}

\section{Extracto:}

Con la globalización, el mundo y su estudio han cambiado, requiriéndose de nuevos aportes para un tratamiento más adecuado. Este trabajo responde a las demandas del actual paradigma en desarrollo, tanto en su dimensión general (nueva percepción y gestión social con la globalización, y la preparación de sus operadores) como en la especial, relativa a la educación (de aprendizaje participativo y tecnológico, ayudándose de herramientas como el e-portafolio). En este trabajo se ofrecen una serie de consejos para un aprovechamiento mayor de las sesiones (presenciales y virtuales), gracias al diseño progresivo y programático de materiales de estudio articulados mediante un portafolio con soporte electrónico.

Palabras claves: innovación docente, aprendizaje electrónico, portafolio electrónico, tecnologías de la información y la comunicación (TIC).
Fecha de entrada: 19-01-2016

Fecha de aceptación: 15-02-2016

\footnotetext{
Dr. A. Sánchez-Bayón, profesor titular de Ciencias Sociales y Jurídicas de la Agencia Nacional de Evaluación de la Calidad y Acreditación (ANECA) y profesor asociado de Ciencias de la Comunicación de la Universidad Camilo José Cela (UCJC). Investigación realizada en el seno del Grupo de Investigación de Derecho y Estudios Comparados y Globales-Universidad Camilo José Cela (GiDECoG-UCJC) con los siguientes apoyos: Latin American Studies-Baylor University (LAS-BU), European \& Latin American Legal Studies Program-DePaul University (ELLSP-DePaul), Departamento de Historia del Derecho-Universidad Nacional de Educación a Distancia (UNED), EAE Business School-Investigación (EAEInvestigación), Instituto Superior de Protocolo y Eventos (ISPE), Wizner \& Co y Centro de Estudios Universitarios-Universidad Rey Juan Carlos (CEDEU-URJC). Contacto: asbayon@ucjc.edu.
} 


\section{E-learning best practice: case study of e-portiolio}

\section{Abstract:}

Under the globalization, the world and it study have changed, requiring new contributions for better treatment. This paper responds the demands about the current paradigm in process, in its overall dimension (new approach and management in the globalization, and training of its agents) and particular on education (technological and pro-acting learning, with tools like e-portfolio). This paper offers a set of tips for better results in the sessions (real or virtual), thanks to progressive and programmatic materials into an e-portfolio.

Keywords: innovative teaching, e-learning, e-portfolio, information and communication technologies (ICT).

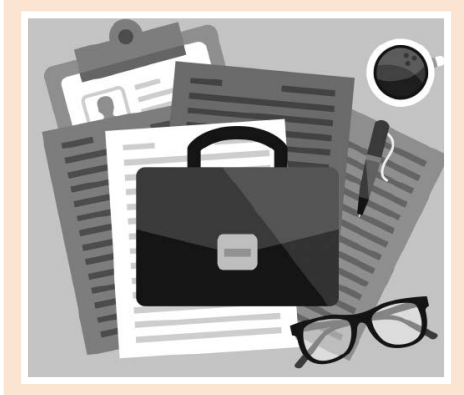

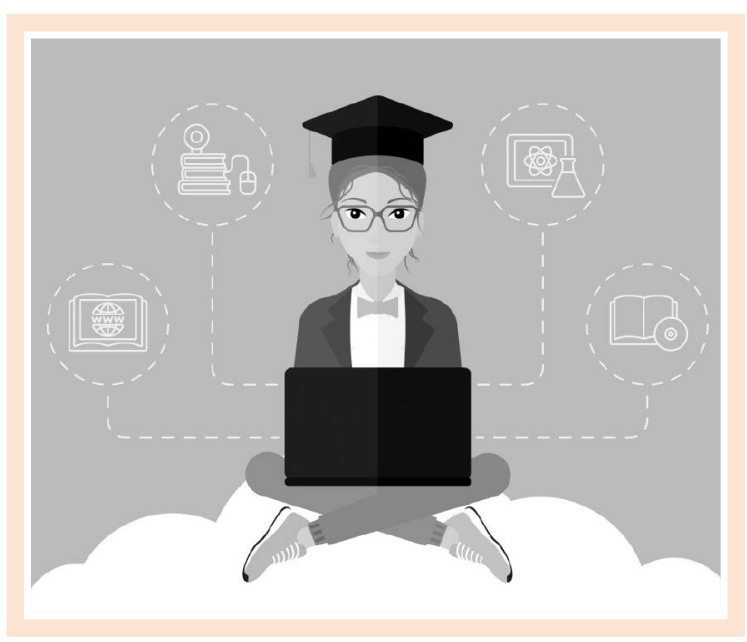

\section{PRESENTACIÓN: CRISIS Y CAMBIO PARADIGMÁTICO}

Vivimos tiempos de crisis o ruptura de tendencia y cierre de ciclo -o fin de la historia, como lo han calificado autores de la talla de Bell, Fukuyama, Huntington, etc.-, para transitar a otro periodo, y de ahí las incertidumbres actuales que nos envuelven [«sociedades líquidas», «de riesgo», «frágiles», "corrosivas», etc. (Sánchez-Bayón, 2012a, 2012b y 2013)]. Frente a tanta inseguridad, en este artículo se pretende aclarar conceptos que permitan comprender y enseñar mejor la realidad de la que formamos parte ( $\sin$ tantas confusiones y con más apoyos; por ejemplo, «TIC»), puesto que dicha realidad social se halla hoy a merced de un proceso transformador llamado «globalización». Téngase en cuenta que la globalización no es un resultado, sino que se insiste en que es un proceso en marcha -de adaptaciones, para alcanzar la anhelada "sociedad del conocimiento», y cuyo primer paso a consolidar es la "gobernanza», que a su vez requiere de operadores preparados para su comprensión y gestión adecuadaJunto con la globalización, que como proceso está teniendo diversas fases de desarrollo [«globalización 1.0», «globalización 2.0», etc. (véase cuadro 1)], han surgido otros conceptos relacionados, como la «glocalización», la «antiglobalización», la «mundialización», etc. (véase cuadro 2). Todo ello se va a exponer y explicar, para hacer comprensible cuál ha sido su origen, evolución y alcance, pues se trata de un proceso que va más allá de la mera internacionalización de mercados, pues también hay una globalización política, jurídica, social, cultural, etc. 


\section{Cuadro 1. Fases de la globalización}

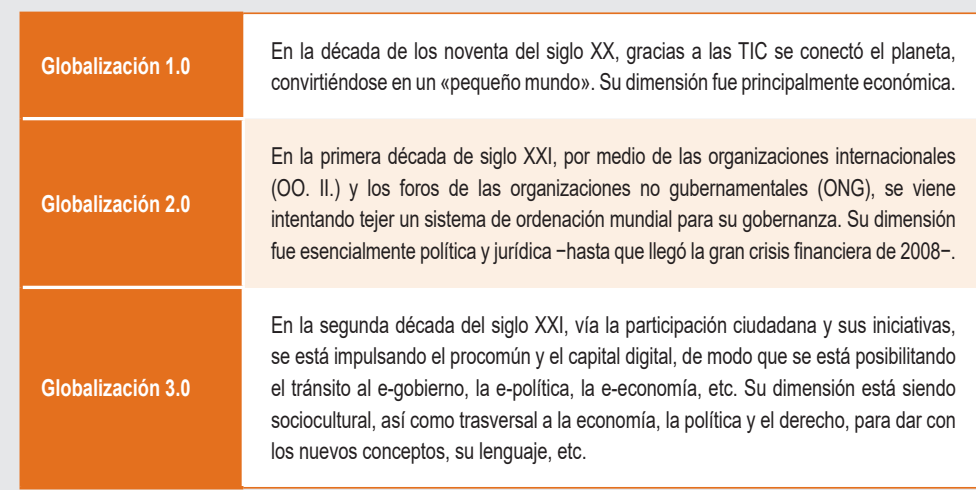

Fuente: elaboración propia

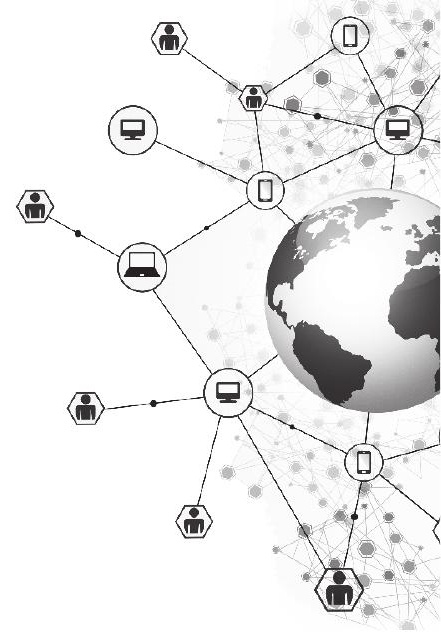

\section{Cuadro 2. Nociones relacionadas con la globalización ${ }^{2}$}

\section{Globalización}

Glocalización

Antiglobalización

Mundialización

Aldea global: espiritu

de San Francisco

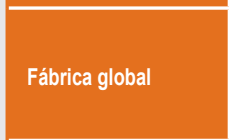

Las Vegas global

Polis global

Apartheid global
Proceso de apertura y convergencia de la humanidad en tiempo real y en todo el mundo (expresión de origen anglosajón).

Proceso de adaptación local frente a la globalización («pensar global, actuar local»; expresión de origen diverso).

Movimientos antisistema (consolidación tras las protestas de Seattle en 1999).

Expresión francesa para referir internacionalización de mercados (mercado-mundo; expresión de origen francófono).

[Carta de la ONU, 1945: «Cap. VIII. «Acuerdos regionales», art. 52: favorecer más organizaciones internacionales para acuerdos pacíficos y textos iushumanistas).

Una economía real a escala planetaria dirigida por la Organización Mundial del Comercio (OMC), la Organización para la Cooperación y el Desarrollo Económicos (OCDE), la Unión Europea (UE), el Mercado Común del Sur (MERCOSUR), el Área de Libre Comercio de las Américas (ALCA), el Tratado de Libre Comercio (TLC), etc.

Un mundo financiero de agentes de bolsa y supervisado por los bancos centrales y el Grupo Banco Mundial [con el Fondo Monetario Internacional (FMI)].

Un amago de gobernabilidad mundial sin gobierno concentrado, sino por medio de una red de organizaciones internacionales y foros mundiales.

La tríada Asia-Pacífico, Europa occidental y América del Norte, como focos que sustentan el poder y el resto del mundo es dependiente -incluso, dentro de estos entornos, las desigualdades son grandes y variadas-, etc.

Fuente: elaboración propia.

\footnotetext{
${ }^{2}$ Se desprende así que globalización, en consecuencia, es un complejo y poliédrico proceso de crisis, transformaciones y transiciones, llamado a movernos de un tiempo rígido monopolizado por el Estado-nación y el materialismo, para trasladarnos hacia la apertura y flexibilidad de la aldea global y su sociedad del conocimiento. Por tanto, ni apocalípticos (contestatarios), ni integrados (legitimadores), sino vigías de unas aguas ignotas que hay que surcar (Sánchez-Bayón, 2012a, 2012b y 2013).
} 
En definitiva, este artículo pretende ser una guía para los responsables de preparar a los operadores de la globalización, en concreto, a los egresados universitarios (tras su adecuada formación -entrenamiento en habilidades y destrezas-, educación -aprendizaje de reflexión crítica autónoma- e instrucción -comprensión de bagajes científicos y culturales existentes-). A la postre, se busca que, con prácticas como el e-portafolio (o carpeta de aprendizaje electrónica, cuestiones a desarrollar en el siguiente epígrafe), los citados operadores de la globalización sepan así dotarse de materiales que les ayuden en su misión de diagnosticar y pronosticar sobre sus entornos, diseñando y aplicando sus enfoques, técnicas y estrategias de exposición a la globalización (y glocalización), ajustándose al ideario (filosofía, valores, cultura, etc.) y requerimientos de sus correspondientes medios sociales (por ejemplo, empresas, ONG, Estados, organizaciones internacionales).

En cuanto al "cambio paradigmático», más allá de lo teorizado por grandes expertos como Kuhn, sirva como explicación la siguiente metáfora: se trata de las «gafas intelectuales con las que vemos la realidad» (Sánchez-Bayón, 2014; Manzanero, 2014). Eso implica, de partida, el tener que reconocer que:

- Nuestra visión es limitada y deficitaria.

- Se requiere de una graduación periódica, por si hubiera variado.

- No todos necesitan de dicha graduación, aunque sí es similar prácticamente en todo el mundo.

Tales postulados se cumplen porque un paradigma solo resulta válido en tanto en cuanto permita resolver los problemas y retos acaecidos en nuestra realidad, pero si no cumple tal misión, ello significa que su tiempo ha pasado $y$ ha de pensarse en «corregir la graduación de las gafas o hacer unas nuevas, para ver mejor». En consecuencia, el e-portafolio es una suerte de prueba de autodiagnóstico para comprobar qué tal va nuestra visión del mundo.

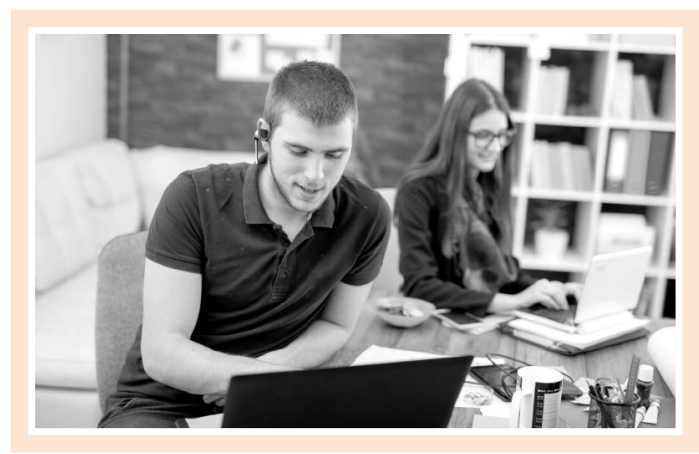

\section{VISIÓN GENERAL DEL PORTAFOLIO EN LOS NUEVOS ESTUDIOS UNIVERSITARIOS}

La doctrina pedagógica, pese a no usar la misma denominación para la herramienta aquí tratada (llamándola por igual portafolio, portafolios, carpeta de aprendizaje, etc., y en este trabajo portafolio), suele coincidir en su concepción, entendiendo por tal la metáfora del maletín donde se guardan y transportan los documentos más relevantes. Aplicándose esta metáfora a la educación, se alude así a la carpeta de aprendizaje donde se van introduciendo los apuntes y resúmenes de las unidades didácticas, junto con sus materiales de trabajo (por ejemplo, banco de preguntas, glosario) y de evaluación (por ejemplo, test de autoevaluación, controles de unidad o bloque), más aquellos otros complementarios, como revista de prensa, comentario de texto, puzle, reseña (Sánchez-Bayón, 2014). Y hasta aquí llega el consenso doctrinal, pues luego depende de cada maestro y sus discípulos -y es que con cada promoción varía: las hay más o menos participativas, con o sin inquietud, estimulables o no, etc.-

En realidad, aunque sean los pedagogos de hoy en día los que pretendan monopolizar el portafolio, se trata de un «redescubrimiento del Mediterráneo» (Sánchez-Bayón, 2010): el portafolio es el apparatus actual, como lo fuera en su momento las recollecta y summa (en el Medievo), hasta los «manuales» y «cursos» (en la contemporaneidad). En concreto, guarda relación con los primeros materiales de aprendizaje universitario, como fueran los «bártulos», de ahí expresiones tales como «recoger los bártulos», «tirarse a la bartola», etc. -cuyo nombre se recibe de su supuesto autor: Bartolo de Sassoferrato (s. XIV)-. 
Se trataba de los apuntes de las lectiones o lecciones, y las cuestiones más relevantes de las diputaciones (preguntas que se planteaban al instructor en la segunda parte de las clases, según el método escolástico), junto con referencias a lecturas complementarias. Dichos materiales fueron supervisados por el profesor, aunque a la postre fueron los estudiantes quienes cobraron protagonismo en su diseño, condicionando el aprendizaje de las promociones venideras. Se apunta todo ello no solo para hacer «memoria universitaria» (Sánchez-Bayón, 2010 y 2013), sino para retirar el velo de confusión por el que la corriente del «constructivismo» pretende atribuirse la autoría del portafolio, y con ello su propiedad, controlando su gestión. A efectos prácticos, y como hito más inmediato, el portafolio, como tal (stricto sensu), surge en los años ochenta del siglo pasado en los EE. UU. al detectarse por la Administración el empobrecimiento y caída de resultados en el aprendizaje de los estudiantes, por lo que se impuso la obligación de compilar las evidencias de diverso tipo sobre cómo enseñaba el profesorado y su asimilación por el alumnado. Así se ha recibido para la construcción de los actuales espacios supranacionales de educación superior [por ejemplo, ANECA-ENQA (European Association for Quality Assurance in Higher Education), Programas Erasmus o Garcilaso], usándose el portafolio como elemento clave en las auditorías sobre la calidad del aprendizaje. Igualmente, el portafolio está siendo fundamental en la implementación y consolidación de modalidades educativas, tales como la semipresencial, a distancia o en línea, causa de su tránsito al siguiente estadio, como es el e-portafolio 0 portafolio electrónico/digital, tal como se aclara en el epígrafe inmediato.

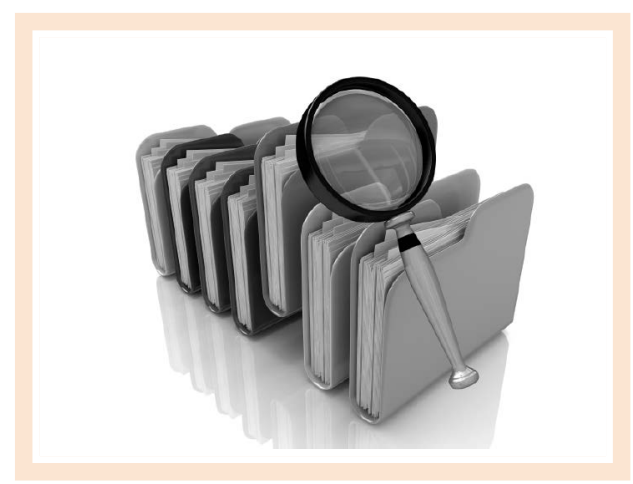

\section{(...) portafolio (...), entendiendo por tal la metáfora del maletín donde se guardan y transportan los documentos más relevantes. Aplicándose esta metáfora a la educación, se alude así a la carpeta de aprendizaje donde se van introduciendo los apuntes y resúmenes de las unidades didácticas, junto con sus materiales de trabajo (...) y de evaluación}

En definitiva, el portafolio es la memoria documentada del proceso de aprendizaje participativo del alumnado (haciendo así corresponsables de su educación a los estudiantes). Supone la recopilación ordenada de materiales seleccionados por cada discente, impulsándose así su iniciativa y autonomía. En consecuencia, aunque el portafolio presupone cierta flexibilidad, hay una serie de contenidos mínimos y una estructura orientativa que hay que observar, conforme a los parámetros fijados en la guía docente. Dicha estructura y sus contenidos son:

- Datos identificativos del alumno y del curso.

- Índice de materiales.

- Síntesis de objetivos (incluidas las competencias que hay que desarrollar) y los contenidos que se deben alcanzar en cada unidad o bloque temático.

- Evidencias o trabajos del alumnado.

- Documentación complementaria (por ejemplo, fuentes de consulta, otros trabajos voluntarios).

A todo ello, desde la experiencia de este autor, resulta conveniente incorporar un apartado en el que los estudiantes puedan reflexionar sobre las evidencias y su proceso de elaboración [similar al one minute test (Sánchez-Bayón, 2014)], además de añadir algún comentario del profesor aclarando la valoración de dichas evidencias y su tratamiento. 


\section{VISIÓN ESPECIAL DEL E-PORTAFOLIO Y LAS PLATAFORMAS EDUCATIVAS TECNOLÓGICAS}

El e-portafolio o portafolio electrónico/digital -también en este caso la doctrina usa una denominación diversa (Barberà, 2006 y 2009; García, 2005; Guasch, 2009; Prendes et ál., 2008), por lo que para este estudio se prefiere e-portafolio- básicamente consiste en un portafolio convencional en el que se ha intensificado el papel de las TIC, lo que ha supuesto las siguientes singularidades -incluso, cabría considerarlas como ventajas, sobre todo para las modalidades educativas no presenciales-:

- Soporte electrónico. Mediante archivos, en su mayoría de ofimática (por ejemplo, Word, ppt, pdf), se logra un menor gasto en papel, plástico (por ejemplo, fundas, encuadernaciones) y metal (por ejemplo, grapas, clips), lo que supone, a la postre, un mayor respeto del medio ambiente (como valor trasversal que hay que inculcar).

- Simultaneidad profesor-alumno. Se logra así una mejor comunicación en tiempo real (vía la propia plataforma educativa, con sus chats, foros, etc.), facilitándose el proceso de aprendizaje.

\section{El e-portafolio o portafolio} electrónico digital (...)

básicamente consiste en un portafolio convencional en el que se ha intensificado el papel de las TIC (...) puede desarrollarse en diversas plataformas y entornos (...), incluso con programas específicos (...) y bajo iniciativas múltiples para su mejor aprovechamiento
- Archivo adecuado de evidencias relativas a la evaluación continua. Toda acción en soporte electrónico tiene su huella digital, reflejándose las fechas y horas; todo ello facilita, entre otras cosas, los procesos de auditoría con agencias de calidad anteriormente citadas (por ejemplo, ANECA).

- Adaptabilidad para el alumnado. Flexibilidad y adecuación a las necesidades e intereses del alumnado en su aprendizaje, volviéndolo realmente participativo, pues, respetándose las directrices básicas de la guía docente, cada estudiante está llamado a desarrollar su autonomía científico-académica (véase epígrafe anterior).

- Entrenamiento en entornos virtuales y ciberrelaciones. Buena parte del alumnado ya es nativo digital, ergo autodidacta digital, sin embargo, suele requerir cierto entrenamiento en un uso adecuado y responsable de dicho entorno, y en un respetuoso y colaborativo actuar en el mismo.

- Aumento de la «metacognición» (Cheng, 2013).

- Etcétera.

El e-portafolio puede desarrollarse en diversas plataformas y entornos (por ejemplo, Moodle, Blackboard), incluso con programas específicos (por ejemplo, Foliotek, Epsilen) y bajo iniciativas múltiples para su mejor aprovechamiento (por ejemplo, IMS ePortfolio Specification, AVENET eFolio). A continuación, se ofrecen una serie de notas breves acerca de dichas iniciativas y los posibles programas o softwares aprovechables ${ }^{3}$.

\footnotetext{
${ }^{3}$ El propio IsPE, como institución educativa a la que está vinculado este autor, lleva lustros liderando la generación y gestión de propuestas, en tal sentido, para centros de enseñanza reglada y no reglada (ONG, academias, formación in-company, etc.). Sin embargo, por pudor académico se ha preferido no citar sus productos y servicios, prefiriéndose invitar a conocerlos a quien desee profundizar en la cuestión (http:// www.protocolo.eu/).
} 


\subsection{Iniciativas para la creación, difusión e inter- operabilidad de e-portafolios}

Entre las pioneras cabe destacar en Europa el portafolio europeo de las lenguas (PEL) o el currículum vítae universal (CVU) ${ }^{4}$, y en EE. UU., ePortfolio California ${ }^{5}$. Se llama la atención sobre las siguientes (entre las 100 primeras):

- IMS ePortfolio Specification. Se trata de una iniciativa gratuita generada por IMS Global para permitir que los e-portafolios sean intercambiables y operativos entre diversos sistemas e instituciones.

- AVENET eFolio. Es una iniciativa de la Administración del estado de Minnesota (siguiendo la estela de ePortfolio California, ya mencionado) para generar e-portafolios útiles para diversas instituciones educativas.

- Educause. Resulta una entidad sin ánimo de lucro, constituida por instituciones docentes, empresas de tecnología educativa y asociaciones del sector, cuyo fin es «mejorar la educación superior mediante el uso de las TIC», facilitándose para ello una rica variedad de programas o softwares.

\footnotetext{
${ }^{4}$ PEL es una iniciativa del Consejo de Europa que permite a los ciudadanos (incluidos estudiantes y trabajadores) poder compartir sus experiencias de aprendizaje, reflexionando sobre las mismas y evaluándolas. CVU es un proyecto del European Institute for E-Learning (ElfEL) para facilitar la tarea de compartir información acerca de su formación y trayectoria laboral.

${ }^{5}$ ePortfolio California es una iniciativa pionera, de los años noventa del siglo XX (y apoyada por las autoridades del estado de California), para promover y fomentar el desarrollo de la formación continua a través de tecnología innovadora y educación cooperativa.
}

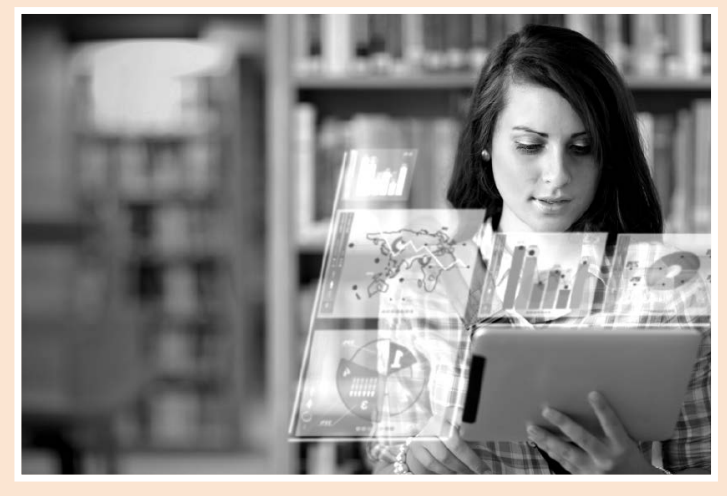

\section{(...) hay que destacar que los alumnos, con el e-portafolio, no solo desarrollan su formación, educación e instrucción (...), adelantándoles a la más que probable experiencia del teletrabajo (...), sino que, además, se les facilita así una carpeta de apoyo laboral de la que disponer, y cuyo formato electrónico posibilita su disposición y adaptación al caso}

\subsection{Programas aprovechables para el e-portafolio}

Buena parte de la doctrina acepta la siguiente clasificación de programas y herramientas para el diseño de e-portafolios:

- Software genérico. Son aplicaciones comunes a otras funciones para crear documentación (por ejemplo, Word, pdf, iMovie), compartirla (por ejemplo, Wetransfer) o estructurar páginas (por ejemplo, Google+, Dreamweaver).

- Software comercial específico. De origen empresarial y de pago (por ejemplo, Digication, Foliotek -incluso, en la nube, como Epsilen-).

- Software libre específico. Similar al comercial, pero gratuito y adaptable; destaca The Open Source Portfolio Initiative (OSPI).

- Software propio. Desarrollado por los propios centros y sus usuarios, como bases de datos compartidas [por ejemplo, learning record on-line (LRO), Denver University portfolio (DUP)].

- Redes sociales. Desde foros, blogs, wikis, Google Apps, etc. 


\section{CONCLUSIONES Y RECOMENDACIONES}

Por razones obvias, de limitación material, se está en la obligación de poner fin -en otro caso, no solo se habrían extendido las explicaciones acerca de las exposiciones realizadas, sino que, además, se habrían tratado temas tan interesantes y derivados como el $\mathbf{m}$-portfolio (la aplicación del e-portafolio a los dispositivos móviles, como el celular), el netfolio (la gestión en red del portafolio, con sus correspondiente comunidades de aprendizaje colaborativo), etc.-. Eso sí, se acomete bajo tal prevención y, para satisfacer uno de los requisitos elementales de todo trabajo científico-académico, se ofrecen a continuación un serie de consideraciones de cierre, más algún consejo para su implementación.

Amén de modas, los orígenes mismos de la universidad y la ciencia moderna (con la Escuela de Cánones y Leyes de Bolonia, hacia el año 1088), siempre ha habido unos materiales de aprendizaje (por ejemplo, recollecta, bartolii), como se ha aclarado, de apparatus o formato similar al actual portafolio. El e-portafolio solo es un paso más en la evolución de la cuestión: se trata del aprovechamiento de las TIC para enseñar mejor a las generaciones de nativos tecnológicos. Ergo, que no se sientan excluidos ni impedidos aquellos de generaciones previas, como puedan ser en gran medida el profesorado vigente -y seguro que bastantes de los lectores de estas páginas, quienes anden buscando su reconversión al nuevo paradigma del aprendizaje participativo, apoyado en las TIC-. Los maestros no lo son por el dominio tecnológico, ni se les pide tal cosa para la aplicación del eportafolio, sino que guíen en un uso adecuado y responsable de las TIC, alentando la iniciativa y autonomía del alumnado, además de estimular su respuesta resolutiva, expeditiva y colaborativa, que tanto se demanda en la sociedad de la información de la que formamos parte.

\section{(...) siempre ha habido unos materiales de aprendizaje (...) El e-portafolio solo es un paso más (...): se trata del aprovechamiento de las TIC para enseñar mejor a las generaciones de nativos tecnológicos}

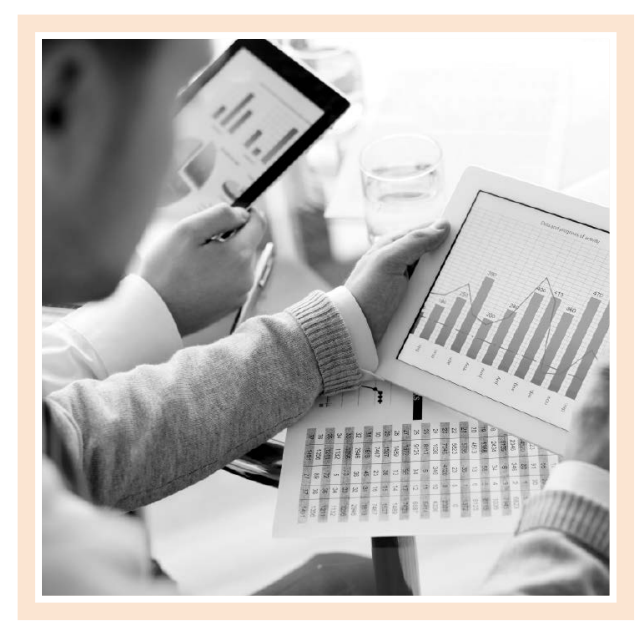

En cuanto a las recomendaciones para un mejor aprovechamiento del e-portafolio, se sugiere lo siguiente: resulta clave dejar claras unas directrices mínimas al respecto, fijadas en la guía docente, recordadas -al menos- el primer día de clase, así como antes de las evaluaciones. Entre dichas instrucciones, no solo han de figurar los puntos mínimos que hay que tratar (con aclaraciones sobre los fines y objetivos), sino también alguna plantilla que inspire el inicio del trabajo estudiantil. Además, se recomienda distinguir entre materiales y actividades obligatorias y voluntarias, instándose desde el primer momento a aspirar a la máxima calificación.

Otro aspecto relevante que hay que destacar es el tocante a la evaluación continua de la que forma parte el e-portafolio, pues no se calificará sin más el documento resultante, sino que el grueso de la nota corresponde al proceso de aprendizaje, por lo que se irá calificando cada parte del e-portafolio con sus trabajos correspondientes (a través de elementos, actividades, controles, etc., y para ello las plataformas digitales son muy útiles, sobre todo, para el cumplimiento de plazos). Algo que valoran mucho los alumnos es que se les vaya indicando sobre la marcha si el portafolio va siendo apto o no, y que las preguntas y ejercicios de la prueba de conocimiento final se identifiquen claramente con el portafolio ( $y$, por ende, también con la guía docente -eso se nota en la actitud en el día del examen y en las posibles revisiones, probando los alumnos su capacidad de autocrítica y responsabilidad-). 
En definitiva, se anima a todos aquellos que aún no han experimentado con el portafolio a que lo hagan, máxime si la modalidad es semipresencial o a distancia. En los cursos on-line resulta irrenunciable si se quiere que los alumnos saquen el máximo provecho posible. Se aconseja que se incentive a los estudiantes para que se tomen su aprendizaje como un teletrabajo, cuyo entorno laboral es la plataforma digital correspondiente, y su e-portafolio es el reflejo de su desempeño: vendría a ser la plasmación de su dirección por objetivos, satisfechos a lo largo del curso, asegurándose así la superación de la materia, con posibilidad de bonus y sin el riesgo de «casino» que supone reducir la calificación a una única prueba de conocimiento en un momento concreto.

Por último, hay que destacar que los alumnos, con el e-portafolio, no solo desarrollan su formación, educación e instrucción (formación: entrenamiento de habilidades y destrezas; educación; reflexión crítica; instrucción: ciencia, arte y cultura recibidos, y obligados a mejorar y transmitir), adelantándoles a la más que probable experiencia del teletrabajo (con sus reglas de juego), sino que, además, se les facilita así una carpeta de apoyo laboral de la que disponer, y cuyo formato electrónico posibilita su disposición y adaptación al caso -con los portafolios convencionales se perdían los materiales con la entrega del incunable al profesor para su evaluación-.

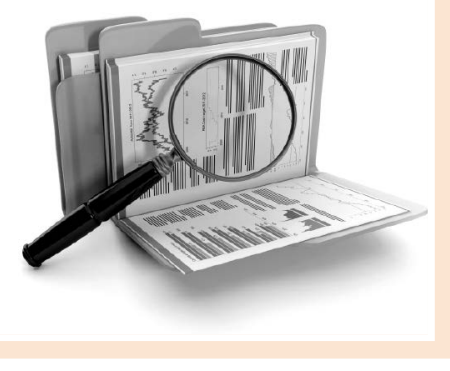

\section{(...) se anima a todos aquellos que aún no han experimentado con el portafolio a que lo hagan, máxime si la modalidad es semipresencial o a distancia. En los cursos on-line resulta irrenunciable si se quiere que los alumnos saquen el máximo provecho posible}

\section{REFERENCIAS BIBLIOGRÁFICAS}

Barberà, E. et ál. [2006]: «Portfolio electrónico: desarrollo de competencias profesionales en la red», Revista de Universidad y Sociedad del Conocimiento, 3 (2), págs. 55-66.

[2009]: Portfolio electrónico: aprender a evaluar el aprendizaje, Barcelona: Editorial UOC.

Cheng, C. [2013]: «Exploring the relationship between students' self-regulated learning ability and their ePortfolio achievement», The Internet and Higher Education, 17, págs. 9-15.

García, F. M. [2005]: «El papel de los portafolios electrónicos en la enseñanza-aprendizaje de las lenguas», Glosas Didácticas, 14, págs. 1-12.

Guasch, T. et ál. [2009]: «Prácticas del portafolio electrónico en el ámbito universitario del Estado Español», Revista de Educación a Distancia, VIII, págs. 1-11.

Manzanero, D. et ál. [2014]: Philosophical challenges of plurality in a global world, Cambridge: Cambridge Scholars Publishing.

Prendes, M. P. et ál. [2008]: «Portafolio electrónico: posibilidades para los docentes», Pixel-Bit. Revista de Medios y Educación, 32, págs. 21-34.

Sánchez-Bayón, A. [2010]. Estudios de cultura político-jurídica, Madrid: Delta Publicaciones.

[2012a]: Filosofía político-jurídica Glocal, Saarbrücken: EAE.

[2012b]: Humanismo iberoamericano. Una guía para transitar la globalización, Guatemala: Cara Parens.

[2013]: Repensar la filosofía social iberoamericana, Valencia: Tirant lo Blanch.

[2014]: Innovación docente en los nuevos estudios universitarios, Valencia: Tirant lo Blanch. 